\title{
MicroRNAs in the Hypothalamus
}

\author{
Björn Meister $^{a} \quad$ Silke Herzer ${ }^{a, b} \quad$ Asli Silahtaroglu ${ }^{c}$ \\ a Department of Neuroscience, Karolinska Institutet, Stockholm, Sweden; ${ }^{b}$ Department of Cellular and Molecular \\ Pathology, German Cancer Research Center, Heidelberg, Germany; ${ }^{C}$ Wilhelm Johannsen Centre for Functional \\ Genome Research, Department of Cellular and Molecular Medicine, and Centre for Non-coding RNA in Health and \\ Technology, Faculty of Health and Medical Sciences, University of Copenhagen, Copenhagen, Denmark
}

\section{Key Words}

Locked nucleic acid $\cdot$ miRNA $\cdot$ Neuroendocrine $\cdot$ Non-coding RNA · Dicer

\begin{abstract}
MicroRNAs (miRNAs) are short ( 22 nucleotides) non-coding ribonucleic acid (RNA) molecules that negatively regulate the expression of protein-coding genes. Posttranscriptional silencing of target genes by miRNA is initiated by binding to the $3^{\prime}$-untranslated regions of target mRNAs, resulting in specific cleavage and subsequent degradation of the mRNA or by translational repression resulting in specific inhibition of protein synthesis. An increasing amount of evidence shows that miRNAs control a large number of biological processes and there exists a direct link between miRNAs and disease. miRNA molecules are abundantly expressed in tissue-specific and regional patterns and have been suggested as potential biomarkers, disease modulators and drug targets. The central nervous system is a prominent site of miRNA expression. Within the brain, several miRNAs are expressed and/or enriched in the region of the hypothalamus and miRNAs have recently been shown to be important regulators of hypothalamic control functions. The aim of this review is to summarize some of the current knowledge regarding the expression and role of miRNAs in the hypothalamus.

(c) 2013 S. Karger AG, Basel
\end{abstract}

\section{KARGER}

E-Mail karger@karger.com

www.karger.com/nen

\section{Introduction}

Characterization of genes that control the timing of larval development in the worm Caenorhabditis elegans led to the discovery of two small regulatory ribonucleic acids (RNAs), lin-4 and let-7 [1, 2]. These small endogenous RNA molecules were later termed microRNAs (miRNAs). Today we know that miRNAs are highly conserved molecules found in plants, green algae, viruses and many different animals, including mammals [3]. miRNAs comprise a large family of endogenous short ( 22 nucleotides) and widely expressed non-coding RNAs that play important gene-regulatory roles by pairing to the mRNA of protein-coding genes to direct their posttranscriptional repression or degradation $[4,5]$. With the potential to target many different mRNAs, individual miRNAs can coordinate or fine-tune the expression of many proteins in a cell. Although the biological functions for only a small fraction of the identified miRNAs have so far been elucidated, an increasing amount of evidence shows that miRNAs control a large number of biological processes, including e.g. cell differentiation, cell death, development, tumorigenesis and regulation of metabolism [4-10]. There exists a direct link between miRNAs and disease [5] and miRNAs have been suggested as potential biomarkers, disease modulators and drug targets $[11,12]$. In recent years, 


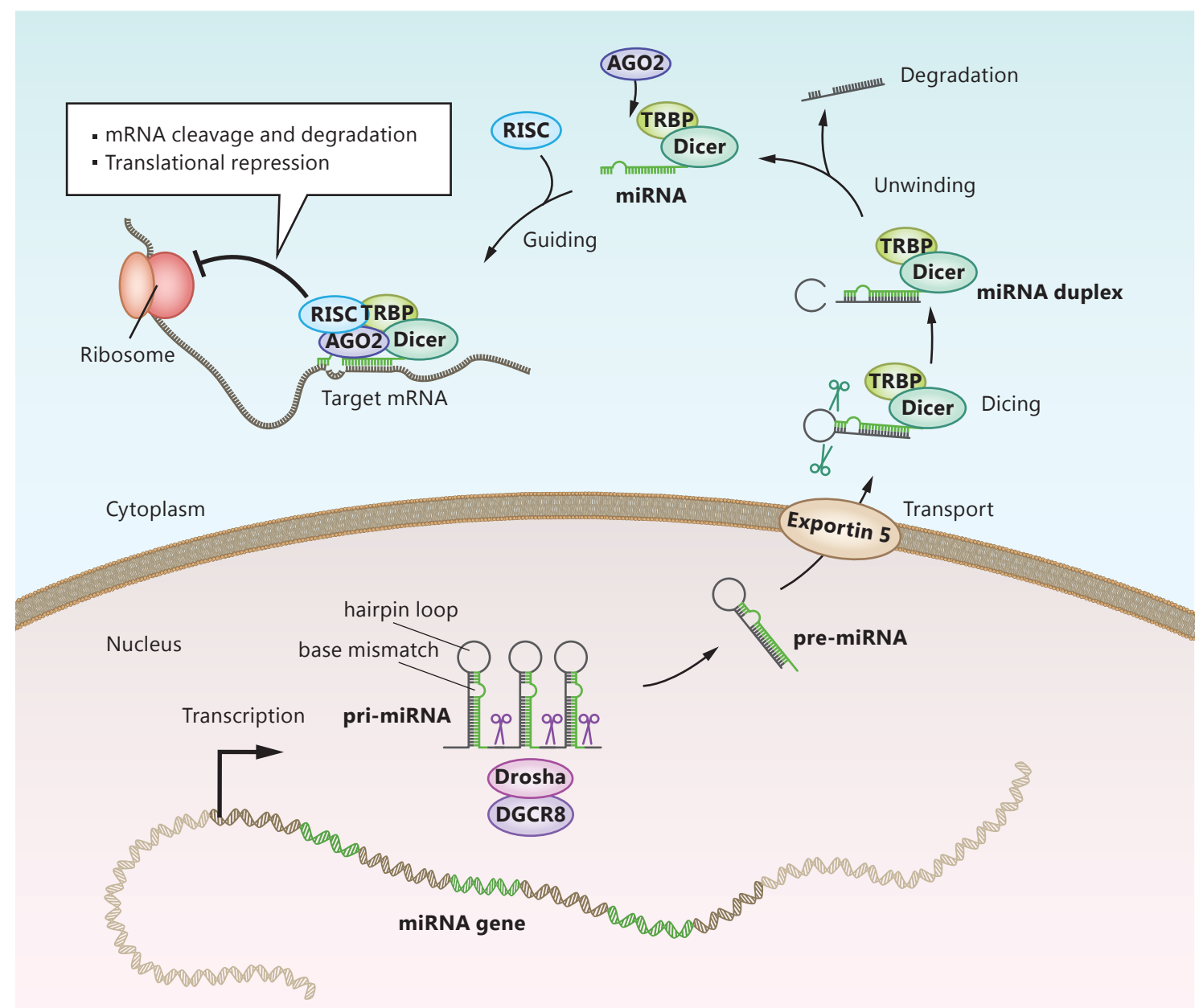

Fig. 1. miRNAs are transcripts derived from independent miRNA genes or from introns of protein-coding genes. miRNAs are transcribed as large polyadenylated pri-miRNA transcripts that can be co-transcribed as clusters encoding up to eight distinct miRNA sequences in a single pri-miRNA transcript. The pri-miRNAs are processed by the RNase III enzyme Drosha together with the dsRNA-binding protein DGCR8 (known as Pasha in invertebrates). The Drosha-DGRC8 complex processes pri-miRNA into a $~ 70$ nucleotide precursor hairpin (pre-miRNA), which is exported to the cytoplasm via the protein Exportin 5. In the cytoplasm, the terminal loop of the hairpin in the pre-miRNA is cleaved (diced) by another RNase II enzyme termed Dicer assisted by TAR TRBP. The remaining 20 base pair miRNA duplex with two nucleotides $3^{\prime}$ overhangs is undergoing unwinding, resulting in ma-

miRNAs have also emerged as important regulators of cellular processes in the central nervous system (CNS), including hypothalamic control functions. This review has the aim to summarize current knowledge on the expression and functional roles of miRNAs in the hypothalamus. ture single-stranded miRNA together with a complex of Dicer and TRBP. Following processing, one strand of miRNA duplex is incorporated into a miRNA-RISC complex, whereas the other strand is released to undergo degradation. In general, the retained strand is the one that has the less stable base-paired $5^{\prime}$ end in the miRNA duplex. AGO2, which has a $\mathrm{RNaseH}$-like endonuclease activity, can support Dicer processing by cleaving the $3^{\prime}$ arm of some premiRNAs and is a key factor in the assembly and function of RISC. RISC will guide the miRNA to its target mRNA, where the miRNA binding will result in mRNA cleavage and subsequent degradation and/or translational repression. In plants, miRNA are more perfectly matched to their target mRNA and use mRNA cleavage rather than translational repression as their primary silencing mechanism.

\section{Synthesis and Processing of miRNAs}

miRNAs are generated from long primary transcripts derived from independent miRNA genes or from introns of protein-coding genes that are processed in multiple steps to cytoplasmic mature miRNA $[4,13]$ (fig. 1). Ani- 
mal miRNAs are initially transcribed by RNA polymerase II as part of one arm of an about 70 nucleotide RNA stemloop. The stem-loop in turn forms part of a several-hundred-nucleotide-long miRNA precursor termed a primary miRNA (pri-miRNA). In the nucleus, the pri-miRNAs fold into hairpins, which act as substrates for the enzyme Drosha (RNase III enzyme) that together with DGCR8 (= DiGeorge syndrome critical region gene 8; dsRNA binding protein; known as Pasha in invertebrates) produce $\sim 70$ nucleotide hairpin loop precursors termed premiRNAs $[13,14]$. The pre-miRNAs are bound to the protein Exportin 5 and exported to the cytoplasm [15]. Here, the pre-miRNAs are further processed by a complex containing a second RNase III enzyme termed Dicer that removes the terminal loop of the hairpin pre-miRNA to generate a $\sim 20-25$ base pair RNA duplex with two nucleotide $3^{\prime}$ overhangs. The dicing generated by Dicer is assisted by transactivation-responsive (TAR) RNA-binding protein (TRBP). The remaining $\sim 20$ base pair miRNA duplex with two nucleotide $3^{\prime}$ overhangs is undergoing unwinding, resulting in mature single-stranded miRNA together with a complex of Dicer and TRBP (fig. 1). The argonaute-2 (AGO2) protein, which has a RNaseH-like endonuclease activity, can support Dicer processing by cleaving the $3^{\prime}$ arm of some pre-miRNAs and is a key factor in the assembly and function of a miRNA-induced silencing complex (RISC) [13]. Following processing, one strand of the miRNA duplex is incorporated into a RISC, whereas the other strand is released to undergo degradation (fig. 1). In general, the retained strand has the less stable base-paired $5^{\prime}$ end in the miRNA duplex. RISC will guide the miRNA to target sequences of mRNA for protein-coding genes, where the miRNA binding will result in mRNA cleavage and subsequent degradation and/or translational repression $[13,16]$. In plants, miRNA are more perfectly matched to their target mRNA and therefore use mRNA cleavage rather than translational repression as their primary silencing mechanism [4].

In order to establish functional roles for miRNAs, a key issue is to find their regulatory targets. In plants, many targets can be predicted by searching for messages with extensive complementarity to the miRNAs [17]. However, in animals, extensive complementarity, with consequent cleavage of the targeted message, occasionally occurs, but is more unusual [18]. Therefore, for metazoan miRNAs, the challenge has been to devise a genomewide computational search that captures most of the regulatory targets. Using algorithms and sets of predictions the miRNA targets can today be evaluated computationally. Several databases exist for predicting metazoan
miRNA targets, including e.g. TargetScan, EMBL, PicTar, EIMMo, Miranda, miRBase Targets, PITA Top and mirWIP [reviewed in 18].

\section{miRNAs in the CNS}

It is evident that miRNAs are expressed in tissue-specific or developmental stage-specific manners. The brain is a major site of miRNA gene expression. Microarray profiling has been used to study the expression profiles in distinct regions of the mouse $[19,20]$ and rat brain $[21]$. Although the regional expression profiles of different miRNAs in the vertebrate nervous system have recently been reported, the cellular localization of individual miRNAs in the nervous system has so far only been clarified to a very limited extent. Furthermore, the chemical phenotypes of miRNA-expressing neurons remain to be established. Studies in zebrafish have provided important information about the spatial expression of miRNA in the nervous system [22]. However, comparison of miRNA expression in the zebrafish and mouse have also revealed divergent expression patterns [20,23]. In fact, it has been reported that more than $50 \%$ of identified mouse CNSenriched miRNAs show different expression patterns compared with those reported in zebrafish [20].

For the in situ detection of miRNA, the use of locked nucleic acid (LNA) probes is currently the most efficient method. LNA nucleotides are used to increase the sensitivity and specificity of expression in DNA microarrays, fluorescent in situ hybridization (FISH) probes, real-time PCR probes and other molecular biology techniques based on oligonucleotides. A chemically synthesized LNA probe contains RNA nucleotides where the ribose moiety is modified with an extra bridge connecting the $2^{\prime}$ oxygen and $4^{\prime}$ carbon. The bridge 'locks' the ribose in the $3^{\prime}$-endo (North) conformation, which is often found in the A-form duplexes. The locked ribose conformation enhances base stacking and backbone pre-organization. This significantly increases the hybridization properties (melting temperature) of oligonucleotides [24]. LNA probes in FISH combined with enhanced detection using tyramide signal amplification represents a powerful method for the detection of miRNA in frozen tissue sections $[25,26]$. LNA-FISH can be combined with immunohistochemistry in order to identify the chemical phenotypes of miRNA-expressing neurons/cells [e.g. 27].

A relatively large number of miRNAs are expressed in the mammalian brain $[28,29]$, but rather little is known about the functions regulated by these brain-expressed 
miRNAs. Some studies have shown roles for miRNAs in neuronal development and differentiation [30-34]. Maternal-zygotic Dicer mutant zebrafish that lack all mature miRNAs display abnormal brain morphogenesis and neural differentiation [35]. Conditional deficiency of the miRNA maturation enzyme Dicer in the developing mouse neocortex leads to massive hypotrophy of the postnatal cortex and death of the mice shortly after weaning [33]. Purkinje cell-specific ablation of Dicer in the cerebellum is associated with the degeneration of Purkinje cells and the development of ataxia in mice [36]; the inactivation of Dicer in the retina results in retinal degeneration [37]. Some neuronal miRNAs appear to be localized to actively translating polyribosomes in dendrites, where they may control local translation of dendrite-specific mRNAs [38]. For example, miR-134, a brain-specific miRNA, is present in dendrites, where it represses the local synthesis of the protein kinase Limk1 to regulate dendritic spine size [39]. miR-138 plays a role in the regulation of axon regeneration [40] and miR-26a promotes neurite outgrowth by repressing PTEN expression [41]. There is increasing evidence for the involvement of miRNAs in diseases of the CNS, including e.g. depression [42], CNS injuries [43] and neurodegenerative disorders [44].

\section{Expression of miRNAs in the Hypothalamus}

Based on an inventory of the miRNA expression profile of 13 areas of the mouse brain using microarray profiling in combination with real-time PCR and LNA-based in situ hybridization, 44 miRNAs showed more than threefold enrichment in the hypothalamus, spinal cord, cerebellum, medulla oblongata, pons, hippocampus, neocortex, olfactory bulb, eye and pituitary gland [20]. The distinct expression patterns with regional enrichment suggest that a large number of mouse CNS-expressed miRNAs may be associated with region-specific functions. In the mouse hypothalamus, miR-7a, miR-7b, miR124a, miR-125a, miR-136, miR-138, miR-212, miR-338, miR-451 and let-7c genes appear to be the most highly expressed miRNAs [20, 21, 27, 45]. Within the hypothalamus, miRNA expression profiling combined with illumina sequencing technology of the arcuate and paraventricular nuclei has revealed that the profiles from the two different nuclei exhibited similar expression from a set of more than 210 miRNA genes [46]. In these two hypothalamic nuclei, particularly high expression was detected for about 20 miRNAs, including seven of the eight genes of the let-7 family, the two miR-7 genes (miR-7a/miR7b), miR-9 gene and a 5' copy of the three miR-30 loci [46]. Three miRNAs that are expressed at particularly high levels in the rat arcuate nucleus and paraventricular nuclei are let-7c, miR-7a and miR-9 [46]. Several studies indicate that miR-7 is particularly enriched in zebrafish [22, 47] and rodent hypothalamus [20, 21, 27] (fig. 2-4). The regional expression pattern for miR-7a in the hypothalamus has been examined in detail using LNA-based in situ hybridization [27] (fig. 2-4). The expression of miR-7a is particularly abundant in the subfornical organ, the suprachiasmatic, supraoptic, paraventricular and arcuate nuclei [27] (fig. 2-4). A comparison of the expression pattern for miR-7a and miR-7b shows that miR-7a has a more restricted expression pattern [27]. Combining LNA-FISH with immunohistochemistry in colchicinetreated rats (a treatment that increases the content of peptides/proteins in the cell soma), it has been possible to establish the chemical phenotypes of miR-7a-expressing neurons in the arcuate nucleus [27] (fig. 4). The results from this study have shown that miR-7a is preferentially expressed in smaller AgRP/NPY neurons located in the ventromedial part of the arcuate nucleus, rather than large POMC/CART neurons encountered in the ventrolateral aspect of the nucleus [27] (fig. 4).

Hypothalamic miRNAs undergo plastic changes during development as demonstrated by experiments using high-throughput Solexa sequencing technology, where a large number of miRNAs were identified and compared in the hypothalamus from 1-day or 36-week-old chicken [48]. Of 371 miRNAs, 22 were upregulated and 157 were downregulated in the 36-week-old chicken as compared to the 1-day-old chicken [48].

\section{Roles of miRNAs in Hypothalamic Regulation}

\section{Control of Food Intake and Body Weight}

In the CNS, the hypothalamus is a key integrator of nutrient-induced signals of hunger and satiety, directing information further to other CNS areas reflecting energy stores and food availability. A subpopulation of neurons in the hypothalamic arcuate nucleus is positioned close to fenestrated vessels allowing facilitated blood-brain exchange. The arcuate nucleus of the hypothalamus contains two crucial populations of orexigenic or anorexigenic neurons that continuously monitor signals reflecting the energy status of the organism. Such hormonal signals include e.g. leptin secreted from the adipose tissue that inhibits food intake and increases energy expendi- 


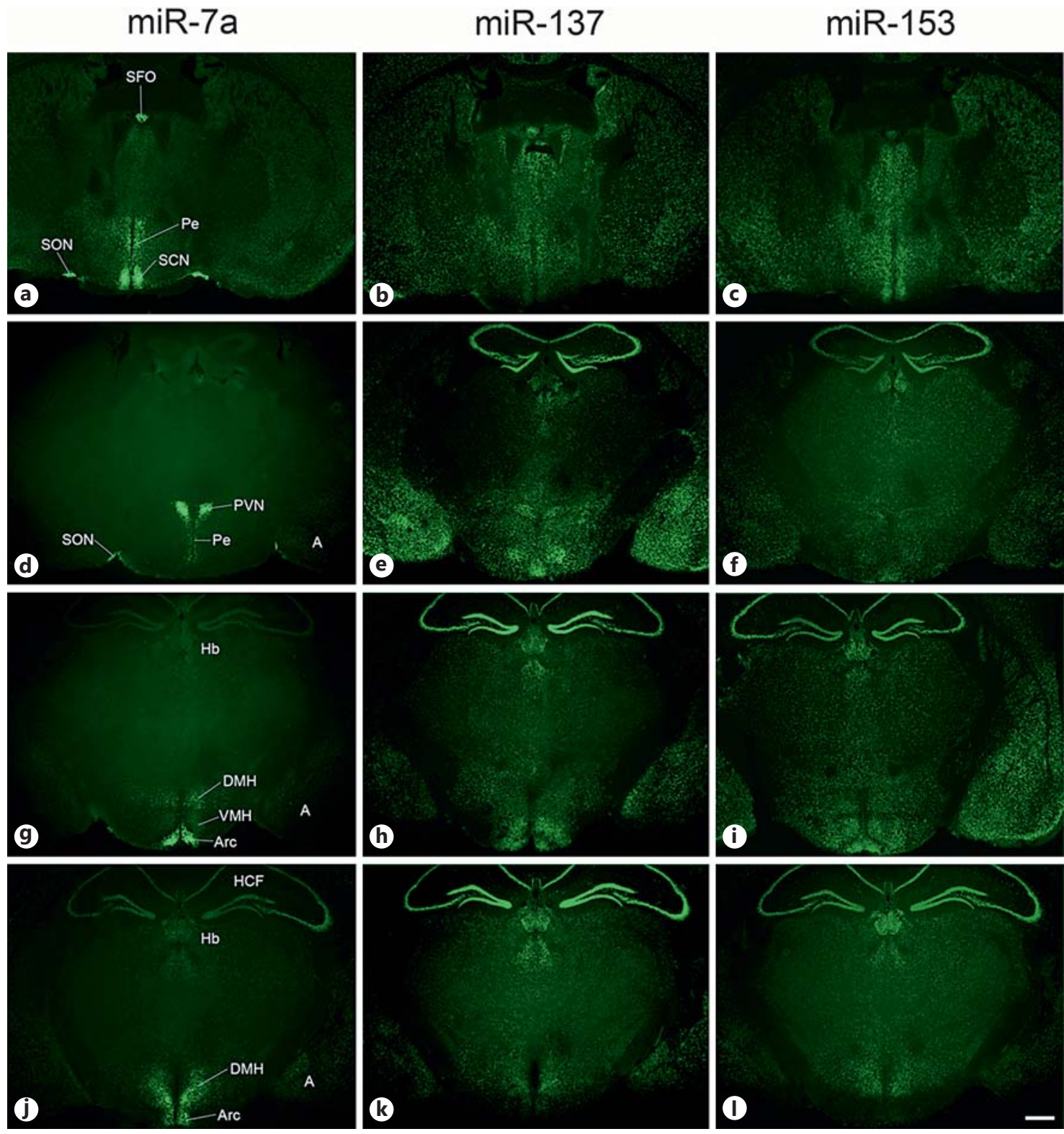

Fig. 2. Images of coronal sections from normal adult male mouse brain after FISH with LNA probes to miR-7a (a, d, g, j), miR-137 (b, e, h, k) and miR-153 (c, f, i, I). All three miRNAs (miR-7a, miR137 and miR-153) are expressed in the hypothalamus. Whereas miR-137 and miR-153 are also highly expressed in other parts of the brain, including e.g. the hippocampal formation (HCF), habenular complex and amygdala, miR-7a is highly enriched in the hypothalamus, with no or low expression in other areas of the brain. Particularly high miR-7a expression is seen in the subfornical organ (SFO), periventricular nucleus $(\mathrm{Pe})$, suprachiasmatic nucleus (SCN), supraoptic nucleus (SON), paraventricular nucleus (PVN), arcuate nucleus (Arc) and dorsomedial hypothalamic nucleus $(\mathrm{DMH}) . \mathrm{VMH}=$ Ventromedial hypothalamic nucleus. Corresponding bregma levels: $\mathbf{a}-\mathbf{c}=-0.46 \mathrm{~mm}$; d-f $=-0.94 \mathrm{~mm} ; \mathbf{g}-$ $\mathbf{i}=-1.70 \mathrm{~mm} ; \mathbf{j}-\mathbf{I}=-2.06 \mathrm{~mm}$. Scale bar $=500 \mu \mathrm{m}$. Modified after Herzer et al. [27]; reproduced with permission from Wiley. 


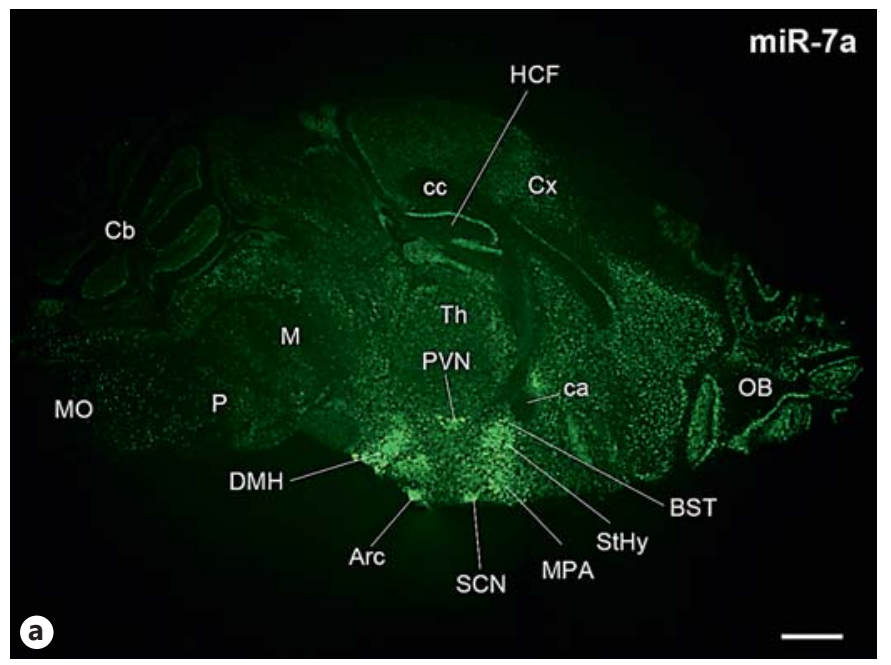

Fig. 3. Images of sagittal (a) and coronal (b) sections from normal adult male mouse brain after FISH with a LNA probe to miR-7a. a In the sagittal section, strong to very strong miR-7a expression is seen in the hypothalamus, including the suprachiasmatic nucleus (SCN), paraventricular nucleus (PVN), arcuate nucleus (Arc), dorsomedial hypothalamic nucleus $(\mathrm{DMH})$, medial preoptic nucleus/area (MPA), bed nucleus of stria terminalis (BST) and striatohypothalamic nucleus (StHy). Weak miR-7a expression is seen in the cerebral cortex $(\mathrm{Cx})$, hippocampal formation (HCF), olfactory bulb (OB) and thalamus (Th). b In the coronal section, very

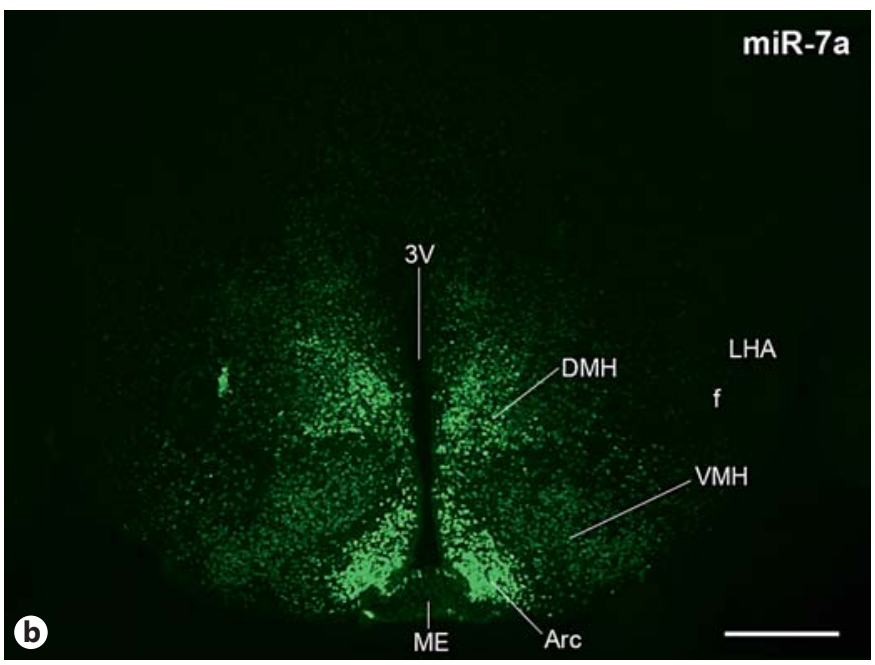

strong miR-7a expression is seen in the ventromedial part of the Arc and in the DMH, whereas the ventromedial hypothalamic nucleus (VMH) shows weak miR-7a expression. Corresponding bregma levels: a Lateral $0.24 \mathrm{~mm}$; b $-1.70 \mathrm{~mm}$. ca = Anterior commissure; $\mathrm{Cb}=$ cerebellum; $\mathrm{cc}=$ corpus callosum; $\mathrm{f}=$ fornix; LHA = lateral hypothalamic area; $\mathrm{M}=$ mesencephalon; $\mathrm{ME}=$ median eminence; $\mathrm{MO}=$ medulla oblongata; $\mathrm{P}=$ pons; $3 \mathrm{~V}=$ third ventricle. Scale bars: $\mathbf{a}=1 \mathrm{~mm} ; \mathbf{b}=0.5 \mathrm{~mm}$. Modified after Herzer et al. [27]; reproduced with permission from Wiley.

logically relevant enzyme implicated in the control of energy balance. Dicer is expressed in most AgRP and POMC neurons of the hypothalamic arcuate nucleus [51]. A key role for Dicer miRNA processing specifically in neurons of the arcuate nucleus has recently been demonstrated by two different research groups $[51,53]$. Dicer is the essential endoribonuclease belonging to the RNase III family that cleaves pre-miRNA into short double-stranded RNA fragments about $20-25$ base pairs long, with a two-base overhang on the $3^{\prime}$-end (fig. 1). Deletion of Dicer-1 in POMC-expressing neurons leads to postnatal cell death in the hypothalamus and pituitary [52]. Mice are born phenotypically normal with normal hypothalamic POMC levels. At 6 weeks of age, no POMC neurons or cells are detected in the hypothalamus and pituitary, respectively, in mutated animals [51, 52]. Conditional deletion of Dicer in POMC-expressing cells results in obesity $[51,52]$. Whereas Schneeberger et al. [51] observed hyperphagia, Greenman et al. [52] showed that the progressive obesity was secondary to decreased energy expenditure, but unrelated to food intake, which in fact was lower than in control mice [52]. The animals exhibited reduced expression of AgRP, NPY and ghrelin receptor in the hypothal- 

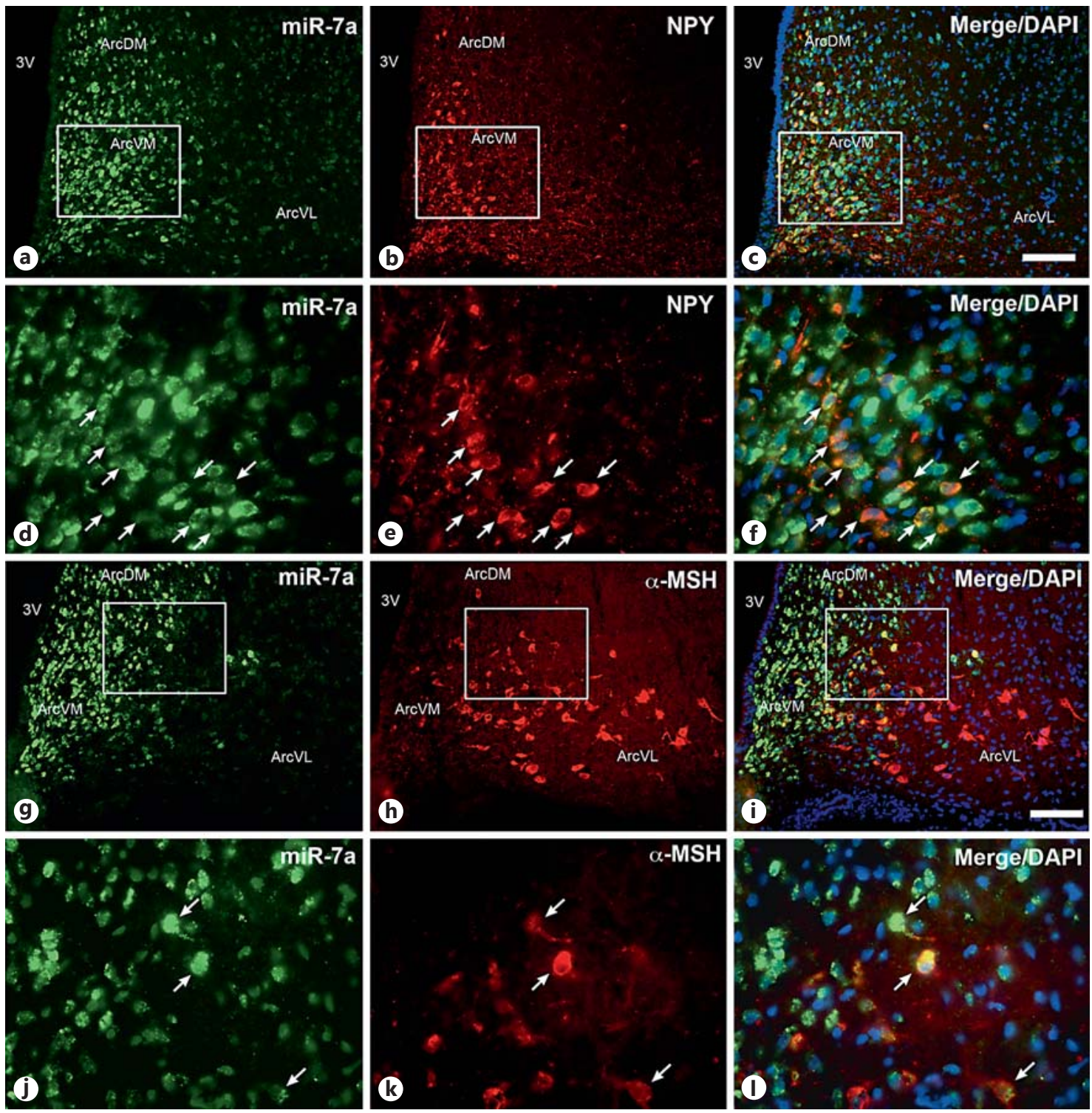

Fig. 4. a-I Images of the hypothalamic arcuate nucleus from colchicine-treated male rats after FISH with a LNA probe to miR-7a (green) and subsequent immunohistochemistry using mouse monoclonal antibodies to NPY (red; $\mathbf{b}, \mathbf{e}$ ) or sheep antiserum to a-MSH, a marker for POMC-containing neurons (red; $\mathbf{h}, \mathbf{k}$ ). Rectangles in $\mathbf{a}-\mathbf{c}$ and $\mathbf{g}-\mathbf{i}$ indicate higher magnifications as shown in $\mathbf{d}-\mathbf{f}$ and $\mathbf{j}-\mathbf{I}$. c, $\mathbf{f}$, $\mathbf{i}$ and $\mathbf{I}$ show the merged images combined with counterstaining using 4',6-diamidino-2-phenylindole (DAPI; blue). Strong miR-7a expression is mainly seen in the ventromedial (ArcVM) and dorsomedial (ArcDM) parts of the arcuate nucleus, whereas the ventrolateral (ArcVL) division of the arcuate nucleus contains only weak or not labeled cell bodies $(\mathbf{a}, \mathbf{g})$. Small NPY-immunoreactive cell bodies are mainly found in ArcVM and contain to a large extent miR-7a expression (compare arrows in d-f). Large $\alpha-\mathrm{MSH}$-immunoreactive cell bodies are mainly found in the ArcVL, with smaller cell bodies distributed in ArcVM. The large $\alpha-\mathrm{MSH}$-immunoreactive cell bodies in the ArcVL are devoid of miR-7a expression, whereas some small a-MSH-immunoreactive cell bodies cell bodies encountered in the ArcVM contain miR-7a expression (compare arrows in $\mathbf{j}-\mathbf{I}$ ). $3 \mathrm{~V}=$ Third ventricle. Scale bar $=500 \mu \mathrm{m}$. Modified after Herzer et al. [27]; reproduced with permission from Wiley. 
amus and reduced uncoupling protein-1 expression in brown adipose tissue [51, 52]. The mutated animals showed a defective glucose metabolism [51, 52]. The fasting glucose levels were dramatically elevated, the glucose tolerance test revealed marked glucose intolerance and the animals had insulin resistance $[51,52]$. Since corticotropes were ablated in the pituitary, basal and stress-induced corticosterone levels were undetectable in the mutated animals. In addition, the animals showed an enhanced anxiety-like behavior [52].

Further evidence for the involvement of miRNA and the hypothalamic control of energy balance comes from a study showing that impairment of leptin action in early life using a pegylated leptin antagonist predisposes fat-fed rats to overweight, promotes insulin/leptin resistance and modifies hypothalamic miRNA at adulthood [54]. The treatment resulted in the particular upregulation of 34 miRNAs and the downregulation of 4 miRNAs of a total of 524 mature rat miRNAs [54]. These results show that impairment of leptin action in early life promotes leptin/ insulin resistance and modifies hypothalamic miRNA expression in adulthood.

The anx/anx anorexia mouse model has a mutation not yet identified located on chromosome 2 , close to the Palladin gene, which exhibits decreased food intake (anorexia-cachexia), growth retardation, ataxia, tremor and hyperactivity [55]. An aberrant expression of miRNA targets and RISC gene expression in the hypothalamus and cortex has been demonstrated in $a n x / a n x$ mice [56]. Five RISC complex-related genes, including Dgcr8, Ago2, Fmr1, Ddx6 and Pabpc1, were upregulated in the hypothalamus of anx/anx mice [56]. Taken together, these results suggest an altered miRNA machinery in the hypothalamus of these animals.

\section{Role in Magnocellular Neurons - Control of Water}

\section{Balance, Lactation and Parturition}

Water balance is regulated via secretion of the neurohypophysial hormone vasopressin which is produced in magnocellular neurons of the hypothalamic paraventricular and supraoptic nuclei to be released from nerve endings in the posterior pituitary. The vasopressin response to osmotic stimuli reflects a cascade of processes including transcriptional regulation, posttranscriptional modulation, cross-regulation by co-expressed neuropeptides, changes in neuropeptide-processing enzymes, and changes in receptor expression and signaling [57]. An analysis of 40 miRNAs that are differentially expressed in the mouse paraventricular and supraoptic nuclei revealed equal numbers of miRNAs that were increased or de- creased after 10 days of drinking $2 \%$ saline (salt loading) [58]. In particular, one miRNA, miR-7b, was studied in detail, since it was highly expressed in the paraventricular and supraoptic nuclei and since sequence analysis revealed that the fos gene was found to have two binding sites for this particular miRNA and therefore was likely to interact with the $3^{\prime}$ UTR of Fos mRNA $[58,59]$. The inducible transcription factor $\mathrm{c}$-fos is known to be upregulated upon salt loading [60]. miR-7b was found to be upregulated in the hypothalamus after chronic hyperosmolar stimulation and to inhibit Fos translation [58]. Increased osmolality activated fos and the transcriptional activation of AP-1, while at the same time increasing expression of miR-7b (via 5 AP1 sites) [58]. The authors showed that miR-7b can act as a functional brake on Fos expression, thereby preventing transcriptional overshoot [59].

Oxytocin is produced in magnocellular neurons of the supraoptic and paraventricular nuclei to be released from nerve endings in the posterior pituitary. Oxytocin has roles in lactation and parturition and influences various behaviors. Recent results show that miR-24 can interact with oxytocin mRNA and inhibit translation and control peptide levels of oxytocin [61].

\section{Control of Circadian Rhythms and Sleep}

Circadian timekeeping mechanisms are present in virtually all living organisms to coordinate daily rhythms in physiology and behavior. Recent studies reveal miRNAs as clock- and light-regulated genes and key regulators of the circadian-timing process [62-64]. miRNAs are expressed in the suprachiasmatic nuclei (SCN), the master circadian clock in mammals, in a rhythmic and inducible fashion, and modulate intrinsic pacemaker activity and resetting capacity of the SCN. miR-219 is a brain-specific miRNA and a target of the CLOCK and BMAL1 complex, which exhibits robust circadian rhythms of expression [65]. The in vivo knockdown of miR-219 lengthens the circadian period [65]. Another brain-specific miRNA, miR-132, is induced by photic entrainment cues via a MAPK/CREB-dependent mechanism, modulates clockgene expression, and attenuates the entraining effects of light [65]. Genes involved in chromatin remodeling (Mecp2, Ep300, Jarid1a) and translational control (Btg2, Paip2a) are direct targets of miR-132 in the mouse SCN [66]. Coordinated regulation of these targets underlies miR-132-dependent modulation of Period gene expression [66]. The mPer 1 and mPer 2 promoters are bound to and transcriptionally activated by Mecp, whereas Btg2 and Paip2a suppress the translation of the PERIOD pro- 
teins by enhancing mRNA decay. Thus, miR-132 is an organizer of chromatin remodeling protein translation via actions on chromatin- and translational-associated target genes in the SCN, thereby fine-tunes the clock entrainment.

In the hypothalamus, miRNA species are both up- and downregulated after sleep deprivation [67]. Intracerebroventricular administration of a miR-132 mimetic (premiR-132) decreases the duration of non-rapid eye movement sleep (NREMS), while simultaneously increasing the duration of rapid eye movement sleep (REMS) during the light phase [68]. Pre-miR-132 decreased electroencephalographic (EEG) slow-wave activity during NREMS. After intraventricular or supracortical injections of pre-miR-132, the mimetic-induced effects specifically occurred only during NREMS. The rat cortical levels of miR-132 were lower at the end of the sleep-dominant light period as compared with the end of the dark period [68]. These results suggest that miR-132 plays a role in sleep regulation. Further studies show that the expression of several miRNAs is changed during sleep deprivation in mice [69]. Furthermore, the levels of multiple miRNAs differ at the end of the sleep-dominant light period versus at the end of the wakedominant dark period in cortical areas, the hippocampus and hypothalamus [70]. In multiple regions of the cortex, miR-138, let-7 and miR-125a expression was higher at the end of the dark period compared with the end of the light period. Intracerebroventricular injection of a specific inhibitor (anti-MIR) to miR-138 suppressed sleep and NREMS EEG $\delta$ power. The anti-MIR to let-7b did not affect time in state, but decreased NREMS EEG $\delta$ power, whereas the anti-MIR to miR-125a failed to affect sleep until after 3 days and did not affect EEG $\delta$ power on any day. It was concluded that miRNAs are uniquely expressed at different times and in different structures in the brain and have discrete effects and varied timings on several sleep phenotypes and therefore are likely to play a role in the regulation of sleep [70].

Role in Development Influencing the Onset of Puberty Lin28 (also termed Lin28a) and Lin28b are related TRBPs that inhibit the maturation of miRNAs of the let-7 miRNA family and participate in the control of cellular stemness and early embryonic development. Dramatic changes in the expression of the Lin28/let-7 axis in the rat hypothalamus have been detected during postnatal maturation and after different manipulations that disturb puberty [71]. In male and female rats and in the monkey hypothalamus, $\operatorname{Lin} 28, \operatorname{Lin} 28 b$ and $c-M y c$ mRNAs showed high hypothalamic expression during the neonatal period
[71]. The levels markedly decreased during the infantileto-juvenile transition and reached minimal levels before/ around puberty [71]. Conversely, let-7a, let-7b, miR-132 and $m i R-145$, but not $m i R-9$, showed opposite expression profiles [71]. Perturbation of brain sex differentiation and puberty by neonatal treatment with estrogen and androgen altered the expression ratios of $\operatorname{Lin} 28 /$ let -7 at the time of puberty [71]. Changes in the $c-M y c / L i n 28 b / l e t-7$ pathway were in addition detected in models of delayed puberty linked to early photoperiod manipulation and, to a lesser extent, postnatal underfeeding or chronic subnutrition [71]. The results together suggest an involvement of hypothalamic Lin28/let-7 in the developmental changes permitting and/or leading to puberty onset [71].

\section{Concluding Remarks}

Non-protein-coding miRNAs have emerged as important regulatory molecules that control almost every cellular process in the organism. The brain is a prominent site of miRNA expression and increasing evidence show that miRNA have many functions in the nervous system. Within the brain, many miRNAs are expressed in the hypothalamus, a region that controls many bodily functions. Some miRNAs show an enrichment in the hypothalamus, suggesting a primary role in hypothalamic regulation. Evidence for the involvement of miRNAs in hypothalamic regulatory functions has recently increased. In the coming years, our knowledge of the cellular localization of miRNAs in the hypothalamus and our understanding of the fundamental roles of miRNAs in hypothalamic regulation are predicted to increase dramatically.

\section{Acknowledgements}

This research was supported by grants from the Swedish Research Council, Funds from Karolinska Institutet, Åhlén-stiftelsen and The Lundbeck Foundation. We thank Mattias Karlén for help with the schematic drawing illustrating the biogenesis of miRNAs.

References

Neuroendocrinology 2013;98:243-253

Lee RC, Feinbaum RL, Ambros V: The C. el egans heterochronic gene lin- 4 encodes small RNAs with antisense complementarity to lin14. Cell 1993;75:843-854.

2 Reinhart BJ, Slack FJ, Basson M, Pasquinelli AE, Bettinger JC, Rougvie AE, Horvitz HR, Ruvkun G: The 21-nucleotide let-7 RNA regulates developmental timing in Caenorhabditis elegans. Nature 2000;403:901-906. 
-3 Griffiths-Jones S, Grocock RJ, van Dongen S, Bateman A, Enright AJ: miRBase: microRNA sequences, targets, and gene nomenclature. Nucleic Acids Res 2006;34:D140-D144.

4 Bartel DP: MicroRNAs: genomics, biogenesis, mechanism, and function. Cell 2004;116: 281-297.

5 Kloosterman WP, Plasterk RH: The diverse functions of microRNAs in animal development and disease. Dev Cell 2006;11:441-450.

6 Wienholds E, Plasterk RH: MicroRNA function in animal development. FEBS Lett 2005; 579:5911-5922.

7 Krützfeldt J, Stoffel M: MicroRNAs: a new class of regulatory genes affecting metabolism. Cell Metab 2006;4:9-12.

8 Hwang HW, Mendell JT: MicroRNAs in cell proliferation, cell death, and tumorigenesis. Br J Cancer 2007;96(suppl):R40-R44.

-9 Schickel R, Boyerinas B, Park SM, Peter ME: MicroRNAs: key players in the immune system, differentiation, tumorigenesis and cell death. Oncogene 2008;27:5959-5974.

$\checkmark 10$ Heneghan HM, Miller N, Kerin MJ: Role of microRNAs in obesity and the metabolic syndrome. Obes Rev 2010;11:354-361.

11 Czech MP: MicroRNAs as therapeutic targets. N Engl J Med 2006;354:1194-1195.

-12 McDermott AM, Heneghan HM, Miller N, Kerin MJ: The therapeutic potential of microRNAs: disease modulators and drug targets. Pharm Res 2011;28:3016-3029.

$\checkmark 13$ Krol J, Loedige I, Filipowicz W: The widespread regulation of microRNA biogenesis, function and decay. Nat Rev Genet 2010;11: 597-610.

14 Han J, Lee Y, Yeom KH, Kim YK, Jin H, Kim VN: The Drosha-DGCR8 complex in primary microRNA processing. Genes Dev 2004;18: 3016-3027.

15 Kim VN: MicroRNA precursors in motion: Exportin-5 mediates their nuclear export. Trends Cell Biol 2004;14:156-159.

- 16 Fabian MR, Sundermeier TR, Sonenberg N: Understanding how miRNAs post-transcriptionally regulate gene expression. Prog Mol Subcell Biol 2010;50:1-20.

$\checkmark 17$ Rhoades MW, Reinhart BJ, Lim LP, Burge CB, Bartel B, Bartel DP: Prediction of plant microRNA targets. Cell 2002;110:513-520.

18 Bartel DP: MicroRNAs: target recognition and regulatory functions. Cell 2009;136:215233.

19 Hohjoh H, Fukushima T: Expression profile analysis of microRNA (miRNA) in mouse central nervous system using a new miRNA detection system that examines hybridization signals at every step of washing. Gene 2007; 391:39-44.

20 Bak M, Silahtaroglu A, Møller M, Christensen M, Rath MF, Skryabin B, Tommerup N, Kauppinen S: MicroRNA expression in the adult mouse central nervous system. RNA 2008; $14: 432-444$.
21 Olsen L, Klausen M, Helboe L, Nielsen FC, Werge T: MicroRNAs show mutually exclusive expression patterns in the brain of adult male rats. PLoS One 2009;4:e7225.

22 Wienholds E, Kloosterman WP, Miska E, Alvarez-Saavedra E, Berezikov E, de Bruijn E, Horvitz HR, Kauppinen S, Plasterk RH: MicroRNA expression in zebrafish embryonic development. Science 2005;309:310-311.

23 Ason B, Darnell DK, Wittbrodt B, Berezikov E, Kloosterman WP, Wittbrodt J, Antin PB, Plasterk RH: Differences in vertebrate microRNA expression. Proc Natl Acad Sci USA 2006; 103:14385-14389.

24 Kaur H, Arora A, Wengel J, Maiti S: Thermodynamic, counterion, and hydration effects for the incorporation of locked nucleic acid nucleotides into DNA duplexes. Biochemistry 2006;45:7347-7355.

25 Silahtaroglu A, Pfundheller H, Koshkin A, Tommerup N, Kauppinen S: LNA-modified oligonucleotides are highly efficient as FISH probes. Cytogenet Genome Res 2004;107:3237.

26 Silahtaroglu AN, Nolting D, Dyrskjøt L, Berezikov E, Møller M, Tommerup N, Kauppinen S: Detection of microRNAs in frozen tissue sections by fluorescence in situ hybridization using locked nucleic acid probes and tyramide signal amplification. Nat Protoc 2007;2:2520-2528.

27 Herzer S, Silahtaroglu A, Meister B: Locked nucleic acid-based in situ hybridization reveals miR-7a as a hypothalamus-enriched microRNA with a distinct expression pattern. J Neuroendocrinol 2012;24:1492-1504.

28 Sempere LF, Freemantle S, Pitha-Rowe I, Moss E, Dmitrovsky E, Ambros V: Expression profiling of mammalian microRNAs uncovers a subset of brain-expressed microRNAs with possible roles in murine and human neuronal differentiation. Genome Biol 2004;5:R13.

29 Nelson PT, Baldwin DA, Kloosterman WP, Kauppinen S, Plasterk RH, Mourelatos Z: RAKE and LNA-ISH reveal microRNA expression and localization in archival human brain. RNA 2006;12:187-191.

30 Krichevsky AM, Sonntag KC, Isacson O, Kosik KS: Specific microRNAs modulate embryonic stem cell-derived neurogenesis. Stem Cells 2006;24:857-864.

-31 Makeyev EV, Zhang J, Carrasco MA, Maniatis T: The microRNA miR-124 promotes neuronal differentiation by triggering brain-specific alternative pre-mRNA splicing. Mol Cell 2007;27:435-448.

32 Visvanathan J, Lee S, Lee B, Lee JW, Lee SK: The microRNA miR-124 antagonizes the anti-neural REST/SCP1 pathway during embryonic CNS development. Genes Dev 2007;21: 744-749.
33 De Pietri Tonelli D, Pulvers JN, Haffner C, Murchison EP, Hannon GJ, Huttner WB: miRNAs are essential for survival and differentiation of newborn neurons but not for expansion of neural progenitors during early neurogenesis in the mouse embryonic neocortex. Development 2008;135:3911-3912.

34 Meza-Sosa KF, Valle-García D, Pedraza-Alva G, Pérez-Martínez L: Role of microRNAs in central nervous system development and pathology. J Neurosci Res 2012;90:1-12.

35 Giraldez AJ, Cinalli RM, Glasner ME, Enright AJ, Thomson JM, Baskerville S, Hammond SM, Bartel DP, Schier AF: MicroRNAs regulate brain morphogenesis in zebrafish. Science 2005;308:833-838.

- 36 Schaefer A, O'Carroll D, Tan CL, Hillman D, Sugimori M, Llinas R, Greengard P: Cerebellar neurodegeneration in the absence of microRNAs. J Exp Med 2007;204:1553-1558.

37 Damiani D, Alexander JJ, O'Rourke JR, McManus M, Jadhav AP, Cepko CL, Hauswirth WW, Harfe BD, Strettoi E: Dicer inactivation leads to progressive functional and structural degeneration of the mouse retina. J Neurosci 2008;28:4878-4887.

38 Kim J, Krichevsky A, Grad Y, Hayes GD, Kosik KS, Church GM, Ruvkun G: Identification of many microRNAs that copurify with polyribosomes in mammalian neurons. Proc Natl Acad Sci USA 2004;101:360-365.

39 Schratt GM, Tuebing F, Nigh EA, Kane CG, Sabatini ME, Kiebler M, Greenberg ME: A brain-specific microRNA regulates dendritic spine development. Nature 2006;439:283289.

40 Liu CM, Wang RY, Saijilafu, Jiao ZX, Zhang BY, Zhou FQ: MicroRNA-138 and SIRT1 form a mutual negative feedback loop to regulate mammalian axon regeneration. Genes Dev 2013;27:1473-1483.

41 Li B, Sun H: miR-26a promotes neurite outgrowth by repressing PTEN expression. Mol Med Rep 2013;8:676-680.

42 Mouillet-Richard S, Baudry A, Launay JM, Kellermann O: MicroRNAs and depression. Neurobiol Dis 2012;46:272-278.

43 Bhalala OG, Srikanth M, Kessler JA: The emerging roles of microRNAs in CNS injuries. Nat Rev Neurol 2013;9:328-339.

-44 Salta E, De Strooper B: Non-coding RNAs with essential roles in neurodegenerative disorders. Lancet Neurol 2012;11:189-200.

45 Farh KK, Grimson A, Jan C, Lewis BP, Johnston WK, Lim LP, Burge CB, Bartel DP: The widespread impact of mammalian microRNAs on mRNA repression and evolution. Science 2005;310:1817-1821.

46 Amar L, Benoit C, Beaumont G, Vacher CM, Crepin D, Taouis M, Baroin-Tourancheau A: MicroRNA expression profiling of hypothalamic arcuate and paraventricular nuclei from single rats using Illumina sequencing technology. J Neurosci Methods 2012;209:134143 
-47 Tessmar-Raible K, Raible F, Christodoulou F, Guy K, Rembold M, Hausen H, Arendt D: Conserved sensory-neurosecretory cell types in annelid and fish forebrain: insights into hypothalamus evolution. Cell 2007;129:13891400.

-48 Sun GR, Li M, Li GX, Tian YD, Han RL, Kang $\mathrm{XT}$ : Identification and abundance of miRNA in chicken hypothalamus tissue determined by Solexa sequencing. Genet Mol Res. 2012; 11:4682-4694.

49 Nogueiras R, Tschöp MH, Zigman JM: Central nervous system regulation of energy metabolism: ghrelin versus leptin. Ann NY Acad Sci 2008;1126:14-19.

50 Meister B: Neurotransmitters in key neurons of the hypothalamus that regulate feeding behavior and body weight. Physiol Behav 2007; 92:263-271.

-51 Schneeberger M, Jordi Altirriba J, García A, Esteban Y, Castaño C, García-Lavandeira M, Alvarez CV, Gomis R, Claret M: Deletion of miRNA processing enzyme Dicer in POMCexpressing cells leads to pituitary dysfunction neurodegeneration and development of obesity. Mol Metab 2013;2:74-85.

52 Greenman Y, Kuperman Y, Drori Y, Asa SL, Navon I, Forkosh O, Gil S, Stern N, Chen A: Postnatal ablation of POMC neurons induces an obese phenotype characterized by decreased food intake and enhanced anxietylike behavior. Mol Endocrinol 2013;27:10911102.

53 Cansell C, Luquet S: Hypothalamic regulation of energy balance: a key role for Dicer miRNA processing in arcuate POMC neurons. $\mathrm{Mol}$ Metab 2013;2;55-57.

54 Benoit C, Ould-Hamouda H, Crepin D, Gertler A, Amar L, Taouis MJ: Early leptin blockade predisposes fat-fed rats to overweight and modifies hypothalamic microRNAs. J Endocrinol 2013;218:35-47.
5 Maltais LJ, Lane PW, Beamer WG: Anorexia, a recessive mutation causing starvation in preweanling mice. J Hered 1984;75:468-472.

56 Mercader JM, González JR, Lozano JJ, Bak M, Kauppinen S, Sumoy L, Dierssen M, Fernández-Aranda F, Visa J, Gratacòs M, Estivill X: Aberrant brain microRNA target and miRISC gene expression in the anx/anx anorexia mouse model. Gene 2012;497:181-190.

57 Burbach JP, Luckman SM, Murphy D, Gainer $\mathrm{H}$ : Gene regulation in the magnocellular hypothalamo-neurohypophysial system. Physiol Rev 2001;81:1197-1267.

58 Lee HJ, Palkovits M, Young WS III: miR-7b, a microRNA up-regulated in the hypothalamus after chronic hyperosmolar stimulation, inhibits Fos translation. Proc Natl Acad Sci USA 2006;103:15669-15674.

59 Uney JB, Lightman SL: MicroRNAs and osmotic regulation. Proc Natl Acad Sci USA 2006;103:15278-15279.

60 Miyata S, Tsujioka H, Itoh M, Matsunaga W, Kuramoto H, Kiyohara T: Time course of Fos and Fras expression in the hypothalamic supraoptic neurons during chronic osmotic stimulation. Mol Brain Res 2001;90:39-47.

61 Choi JW, Kang SM, Lee Y, Hong SH, Sanek NA, Young WS, Lee HJ: MicroRNA profiling in the mouse hypothalamus reveals oxytocinregulating microRNA. J Neurochem 2013; 126:331-337.

62 Cheng HY, Obrietan K: Revealing a role of microRNAs in the regulation of the biological clock. Cell Cycle 2007;6:3034-3035.

63 Mehta N, Cheng HY: Micro-managing the circadian clock: the role of microRNAs in biological timekeeping. J Mol Biol 2013;425: 3609-3624.
64 Chu C, Zhao Z: MicroRNA in the molecular mechanism of the circadian clock in mammals. Front Biosci 2013;18:441-446.

65 Cheng HY, Papp JW, Varlamova O, Dziema H, Russell B, Curfman JP, Nakazawa T, Shimizu K, Okamura H, Impey S, Obrietan K: MicroRNA modulation of circadian-clock period and entrainment. Neuron 2007;54: 813-829.

66 Alvarez-Saavedra M, Antoun G, Yanagiya A, Oliva-Hernandez R, Cornejo-Palma D, Perez-Iratxeta C, Sonenberg N, Cheng HY: miRNA-132 orchestrates chromatin remodeling and translational control of the circadian clock. Hum Mol Genet 2011;20:731-751.

67 Davis CJ, Bohnet SG, Meyerson JM, Krueger JM: Sleep loss changes microRNA levels in the brain: a possible mechanism for state-dependent translational regulation. Neurosci Lett 2007;422:68-73.

68 Davis CJ, Clinton JM, Taishi P, Bohnet SG, Honn KA, Krueger JM: MicroRNA-132 alters sleep and varies with time in brain. J Appl Physiol 2011;111:665-672.

69 Mongrain V, Hernandez SA, Pradervand S, Dorsaz S, Curie T, Hagiwara G, Gip P, Heller HC, Franken P: Separating the contribution of glucocorticoids and wakefulness to the molecular and electrophysiological correlates of sleep homeostasis. Sleep 2010;33:1147-1157.

70 Davis CJ, Clinton JM, Krueger JM: MicroRNA-138, let-7b, and 125a inhibitors differentially alter sleep and EEG delta-wave activity in rats. J Appl Physiol 2012;113:17561762.

71 Sangiao-Alvarellos S, Manfredi-Lozano M, Ruiz-Pino F, Navarro VM, Sánchez-Garrido MA, Leon S, Dieguez C, Cordido F, Matagne V, Dissen GA, Ojeda SR, Pinilla L, TenaSempere M: Changes in hypothalamic expression of the Lin28/let-7 system and related microRNAs during postnatal maturation and after experimental manipulations of puberty. Endocrinology 2013;154:942-955. 